\title{
Introgression the SALTOL QTL into Q5DB, the elite variety of Vietnam using marker- assisted - selection (MAS)
}

\author{
Luu Thi Ngoc Huyen, Luu Minh Cuc, Le Huy Ham, Tran Dang Khanh* \\ Molecular Biology Division, Agricultural Genetics Institute, Pham Van Dong Road, Tuliem, Hanoi, Vietnam
}

Email address:

khanhkonkuk@gmail.com (T. D. Khanh)

\section{To cite this article:}

Luu Thi Ngoc Huyen, Luu Minh Cuc, Le Huy Ham, Tran Dang Khanh. Introgression the SALTOL QTL into Q5DB, the Elite Variety of Vietnam Using Marker- Assisted - Selection (MAS). American Journal of BioScience. Vol. 1, No. 4, 2013, pp. 80-84. doi: $10.11648 /$ j.ajbio.20130104.15

\begin{abstract}
Rice is a main food crop in Vietnam and plays a key role in economic growth in this country. However, its production and cultivating areas are severely affected from the threats of devastation caused by the rise of sea level. In this study, we have focused on developing new rice lines with salinity tolerance and high yield by applying markers assisted selection (MAS). Total of 21 primers in the Saltol QTL region were checked with the two parents varieties to identify polymorphic primers for screening the Saltol QTL region of the breeding populations. The individual plants in BC1, BC2, and BC3 generations of the Q5DB/FL478 were analyzed to evaluate the introgression of Saltol fragment into Q5DB cultivar. After screening of 3 BC generations, the best individual plants of BC3F1 of the plant numbers QF-3-1, QF-3-2, QF4-3-3, QF6-3 with almost the recipient alleles were selected. Conventional breeding was developed on BC3F2 for selection of the new salt tolerance rice lines with high yield, resistance to the biotic stress. The salinity tolerance of the new lines was also performed using the standard system of screening.
\end{abstract}

Keywords: Q5DB, Marker Assisted Selection, Rice, Saltol- QTL

\section{Introduction}

Salinity is one of the major serious factors limiting the productivity of rice crop in many worldwide countries. Over 45 million hectares of irrigated land have been damaged by salt, and 1.5 million hectares are taken out of production annually as the consequence of high salinity levels in the soil ${ }^{(1)}$. In Asia, 21.5 million hectares of land areas are directly affected by salinity and estimated to cause the loss of up to $50 \%$ fertile land by the $21^{\text {st }}$ midcentury ${ }^{(2)}$.

Rice is a major crop in Vietnam and providing daily food for over 89 million populations in this country. Currently, Vietnam is a leading biggest rice exporter in the world, accounting for $50 \%$ of the world rice trade ${ }^{(3,4)}$. However, salinity affects a very large part of two major rice producing areas of Red River Delta (RRD) and Mekong River Delta (MRD) in this country. With sea level rise by $1 \mathrm{~m}$, approximately $40.000 \mathrm{~km}^{2}$ will be inundated, and salinity intrusion is expected to cover about $71 \%$ of the MRD and RRD. Vietnam is formidably coping with salinity intrusion which has been causing adverse influence on 1 million ha, equally with $3 \%$ of total Vietnam area ${ }^{(5,6)}$. The annual economic loss by salt intrusion is up to 45 million USD, which is equivalent to $1.5 \%$ of rice productivity in the Mekong Delta ${ }^{(7)}$. To overcome reduction of crop yield in salt soil, the attempts of worldwide researchers are conducted by soil reclamation or improving salt tolerance in the target crops. Recently, a rapid progress has been made towards the development of molecular marker technologies and their application in linkage mapping molecular dissection of the complex agronomical traits and marker-assisted breeding ${ }^{(8)}$.

Marker assisted selection (MAS) is simply understood as the use of genetic markers to follow regions of the genome that encode specific characteristics of a plant. Molecular markers for trait selection have numerous advantages over morphological markers used in conventional plant breeding. MAS has been widely applied to monitor the presence or absence of the tolerance genes in breeding population and can be combined with conventional breeding approaches ${ }^{(9)}$. MAS has been used in plant breeding programs for gene introgression and gene pyramiding for improvement of commercially important crops such as rice, wheat, corn, 
soybean, and some vegetables as tomato and paper ${ }^{(10)}$. The basis of MAS strategy is to transfer a gene/QTL from a donor line to a recipient line while selecting against donor introgressions across the rest of the genome ${ }^{(11-13)}$.

Saltol QTL is considered as a main quantitative trait locus (QTL) and was previously identified and detected on the chromosome of the salt tolerance of Pokkali cultivar. This QTL confers as salinity tolerance at the vegetative stage and explains from $64 \%$ to $80 \%$ of the phenotypic variance $^{(14)}$. To date, some recent researches have also detected the same QTL in some other rice cultivars ${ }^{(15-17)}$.

Research at International Rice Research Institute (IRRI) resulted in the development of high yielding rice varieties tolerant of abiotic stress such as submergence and salt stress, and these varieties can help make these unfavorable coastal areas less vulnerable to climate change impacts ${ }^{(11)}$. The newly improved varieties have been developed using both conventional and modern breeding tools. Breakthroughs in salinity tolerance breeding became feasible after the identification of major chromosomal regions (Quantitative trait loci, QTLs) underlining salinity (Saltol) stress, and the development and use of a marker system for their speedy incorporation into modern high yielding and popular varieties through marker assisted backcrossing ${ }^{(11)}$.

The objectives of the current study were to introgress Saltol QTL into the widely grown Q5DB rice cultivar by applying the molecular breeding techniques as a valuable tool for rapidly ameliorate the salinity tolerance. The newly improved rice cultivar will be useful for farmers growing rice in the salt affected deltas in Vietnam.

\section{Materials and Methods}

\subsection{Plant Materials}

A highly-salt tolerance FL478 (IR-66964-3R-178-1-1) was imported from IRRI and used as the donor of Saltol QTL, whereas, Q5DB (O.sativa spp.indica) is an elite Vietnamese rice cultivar, which is popularly grown in the north delta of Vietnam, was used as the recipient plant.

For the MAS breeding strategy, F1 seeds were developed by crossing between Q5DB and FL478 cultivars. After that F1 was backcrossed to Q5DB to obtain a large number of BC1F1. BC1F1 plants were screened for Saltol QTL fragment selection. The individual plants carrying target QTL were selected by applying molecular markers for the next $\mathrm{BC}$ generations. Over hundreds of $\mathrm{BC} 2 \mathrm{~F} 1$ and then $\mathrm{BC} 3 \mathrm{~F} 1$ plants were screened for foreground selection. The fewer individual plants of $\mathrm{BC} 2 \mathrm{~F} 2$ or $\mathrm{BC} 3 \mathrm{~F} 1$ carrying target gene with almost recipient genome could be identified.

\subsection{Parents SSR Polymorphism Screening}

Approximately 120 Simple Sequence Repeats (SSR) markers distributed on the 12 chromosomes including both the foreground and background markers were screened.

\subsection{Genotype Data Analysis}

Genotype was obtained by analyzing DNA with SSR markers using $15 \mu \mathrm{L}$ PCR reactions on 96-well plates. After initial denaturation for $4 \mathrm{~min}$ at $94^{\circ} \mathrm{C}$ each cycle comprised 1 min denaturation at $94^{\circ} \mathrm{C}, 1 \mathrm{~min}$ annealing at $55^{\circ} \mathrm{C}$, and $1 \mathrm{~min}$ extension at $72^{\circ} \mathrm{C}$ with a final extension for $5 \mathrm{~min}$ at $72^{\circ} \mathrm{C}$ at the end of 30 cycles (Eppendoft thermal cyclers). The PCR products were mixed with bromophenol blue gel loading dye and were analyzed by electrophoresis on $4.5 \%$ acrylamide gel at $1500 \mathrm{~V}$ (Biorad system) followed by silver stainning steps and scoring; or electrophoresis on $6 \%$ $-8 \%$ acrylamide gels at $100 \mathrm{v}$ (Dual Triple-Wide MiniVertical System, C.B.S.Scientific, CA, USA) followed by SYBR-Safe staining (Invitrogen), gel documentation (Alpha Innotech), and manual scoring of the gel pictures).

\subsection{Statistical Analysis}

The molecular weights of the different alleles were measured using Alpha Ease Fc 5.0 software. The marker data was analyzed using the software Graphical Genotyper (GGT 2.0) (18). The homozygous recipient allele, homozygous dominant allele and heterozygous allele were scored as 'A', 'B' and ' $\mathrm{H}$ '. The percent markers homozygous for recipient parent $(\% \mathrm{~A})$ and the percent recipient alleles including heterozygous plants $(\% \mathrm{R})$ were calculated.

\subsection{Evaluation of Salinity Tolerance}

Pre-germinated $\mathrm{BC} 2 \mathrm{~F} 2$ and $\mathrm{BC} 3 \mathrm{~F} 1$ seeds were sown in the holes on styrofoam floats of a net bottom suspended on trays filled with Yoshida nutrient solution ${ }^{(19)}$. Three replications were used for each experiment, with nine individual plants per line evaluated for each replication. Salt stress was imposed 14 days after germination by adding $\mathrm{NaCl}$ to an EC of $12 \mathrm{dS} \mathrm{m}-1$ in Yoshida nutrient solution until final scoring. IR29 (sensitive) and FL478 (highly tolerant) were used as the checks. The $\mathrm{pH}$ of the nutrient solution was adjusted daily to 5.0, and the culture solutions were replaced every - 5 days. Entries were scored based on visual symptoms using IRRI's Standard Evaluating Score (SES) for rice, with ratings from 1 (highly tolerant) to 9 (highly sensitive) ${ }^{(20)}$.

\section{Results and Discussion}

\subsection{Parental SSR Polymorphism Screening}

A number of molecular markers that have discovered in recent years, of which SSR markers are still indispensable because they show enormous potential to improve and precision of conventional plant breeding through MAS ${ }^{(21-}$ ${ }^{22)}$. In this study, 120 SSR markers on 12 rice chromosomes were used to screen for parental polymorphic markers of both steps of foreground and background selections. In those, 21 primers in the Saltol/QTL region were checked with two parent's varieties in order to find out polymorphic 
primers to further use for screening the Saltol region of the crossing populations. The result showed that 28 markers were polymorphic, including 3 markers AP3206, RM3412 and RM10793 on chromosome 1 which linked to Saltol QTL. This result was agreed with some previous reports to verify the polymorphic markers between the parents in target region of Saltol ${ }^{(23-25)}$. All those markers were used for screening the generations of the $\mathrm{BC} 1 \mathrm{~F} 1, \mathrm{BC} 2 \mathrm{~F} 1$ and $\mathrm{BC} 3 \mathrm{~F} 1$, respectively.

\subsection{Genotyping}

Based on the map of Saltol QTL region, the best markers within the Saltol QTL region were AP3206 and RM3412, the most useful markers flanking the Saltol QTL region were RM10694 (telomeric to Saltol) and RM493 and RM10793 (centromeric to Saltol QTL), while nearby markers that can be used for negative selection are RM490 above Saltol and RM7075 below. Microsatellite markers unlinked to Saltol QTL covering all the chromosomes that were polymorphic between the two parents, were used for the recipient genome. For target Saltol QTL selection, AP3206, RM3412 and RM10793 markers were used for screening heterozygous plants (Fig. 1). Similarity steps were taken with these two crosses. After three generations of screening with 28 markers, combined with conventional breeding, the promising lines Q5DB-Saltol were selected to develop the next generations. Previously, we also have successfully genotyped BC generations by using the above markers of the crossed of the AS996, BT7, the elite Vietnamese rice cultivars (recipient plants) and FL478 (carrying Saltol QTL, as the donor plant) ${ }^{(6,24)}$

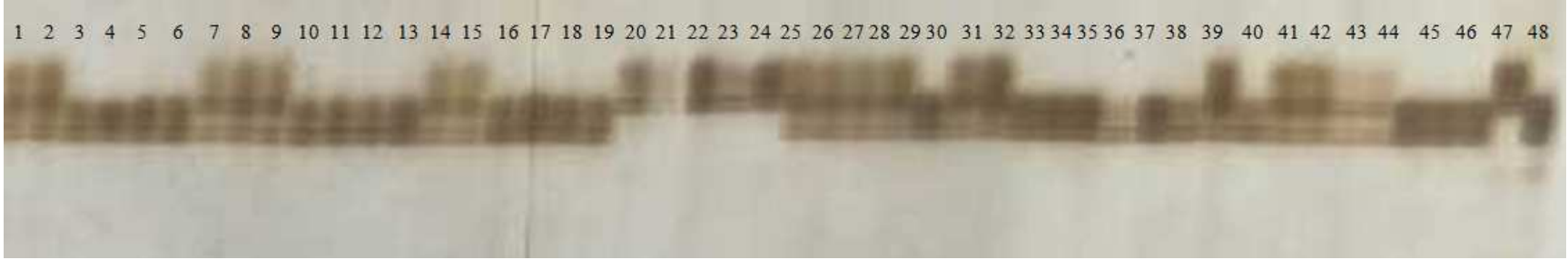

Figure 1. Screening for Saltol QTL in the selected plants in BC3F2 generation of the crossed Q5DB x FL478 for primer AP3206(C). Lane 1- 46: BC3F2 plants, 47: FL478; 48: Q5DB. Plants 20, 22, 23,24 were possessed homozygous DNA band from FL478. The individual plants numbers $3,4,5,6,10,11,12,13,16,17,18,19,29,30,32$ 33,34,36,37,39, 44,45,46 showed homozygous DNA band from Q5DB. Other plants were possessed heterozygous DNA bands

\subsection{Evaluation of Salinity Tolerance of BC2F2 and BC3F1 Plants at Seedling Stage}

The $\mathrm{BC} 2 \mathrm{~F} 2$ and $\mathrm{BC} 3 \mathrm{~F} 1$ seeds were screened to evaluate the introgression of Saltol QTL fragment into Q5DB. After growing three days in deionizer water, Yoshida nutrient solution was added in the trays. Salinisation was commenced once for 3 leaves of seedling. Then, salt in fresh nutrient solution containing the appropriate concentration of salt was applied. Once symptom has progressed to an appropriate extent, when the sensitive check was reached the score value of $7-8$, single aggregate score per genotype.

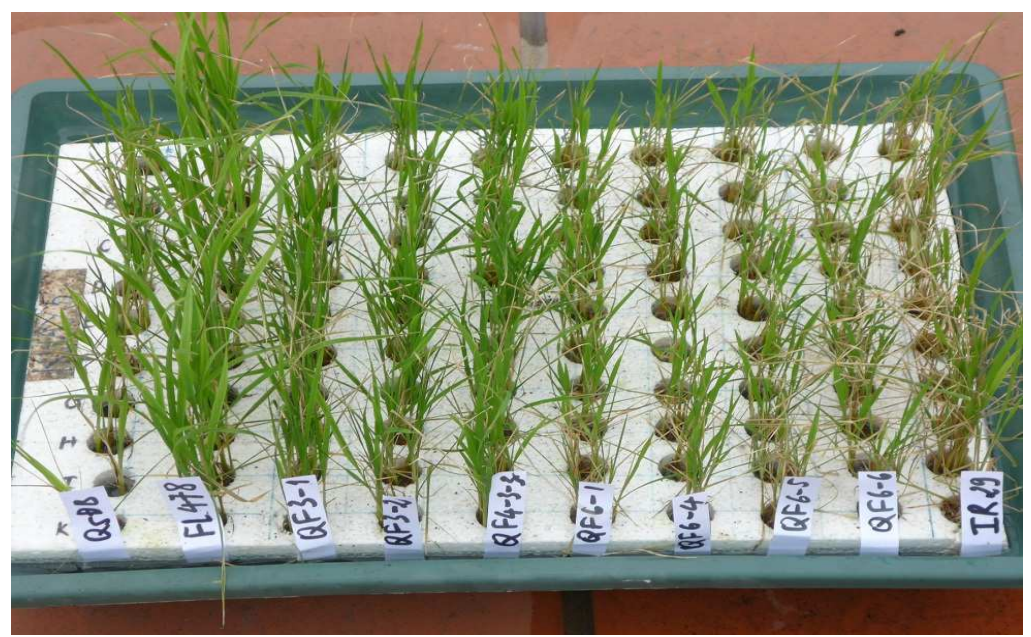

Figure 2. The promising BC3F2 of QF3-1, QF3-2, QF4-3-3, QF6-4, QF6-5, QF6-6 (Q5DB-Saltol) lines at finishing the salinisation at EC=12dSm $\left(\mathrm{NaCl}=6^{\circ} \%\right.$ ).

Similarly, BC3F2 seeds were screened to evaluate the introgression of Saltol fragment into Q5DB line. Salt stress was imposed 14 days after germination by adding $(\mathrm{NaCl}=$ $6 \%$ ) to an EC of $12 \mathrm{dS} \mathrm{m-1} \mathrm{in} \mathrm{Yoshida} \mathrm{nutrient} \mathrm{solution}$ until final scoring. Based on visual symptoms using IRRI's SES for rice, when the susceptible variety IR29 (sensitive) scored 9 and variety FL478 were used as highly tolerant checks scored 3, all the BC3F2 of the selected plants QF-3- 
1, QF-3-2, QF4-3-3, having the same score as the tolerant checks. It means that the homozygous Saltol fragment working well in $\mathrm{BC} 3 \mathrm{~F} 2$ generation. The $\mathrm{BC} 3 \mathrm{~F} 1$ plants QF6-4, QF6-5, QF6-6 lines scored 3-5 because of the heterozygous of Saltol fragment (Fig. 2).

The potential QF3-1, QF3-2, QF4-3-3 lines were grown in the costal saline areas in Tien Hai, Thai Binh provinces, Red River Delta of Vietnam in the spring crop season of 2013 for the salinity tolerance of field evaluation. The best lines of the QF3-1, QF3-2, QF4-3-3 lines showed high yield and biotic stress tolerance (fungi, insect) on the field. Specifically, the QF3-1 and QF3-2 lines were exhibited the real yield 6.5- 6.7 ton/hectare in the saline level $\mathrm{NaCl}=3 \%$ that higher than the Q5DB (only 5.1-5.8). Based on observation, in general the morphologic of the QF3-1 and QF3-2 lines shows mostly similar with the recurrent parent (Q5DB cultivar) such as day to heading, secondary plant number, panicle number, primary plant number, seed per panicle, spikelets per panicle (unpublished data). Noteworthily that in unsalted field, the QF3-1 and QF3-2 lines have exhibited the real yield 7.5- 8.2 ton/hectare, while the Q5DB was shown the real yield 7.1-7.9 ton/hectare. Markers assisted selection (MAS) as a high technology tool for breeding was used in this study, integrated with conventional breeding. The promising rice lines Q5DB-Saltol possesing Saltol QTL with the similar morphologic Q5DB cultivar was selected. The salinity tolerance level of the promising lines was shown as the tolerance check FL478 line. The real yield of the promising line QF3-1 was 6.5- 6.7 ton/hectare to compared with the yield 6.3 ton/hectare of the recipient variety Q5DB on the saline level $\mathrm{NaCl}=3 \%$ field.

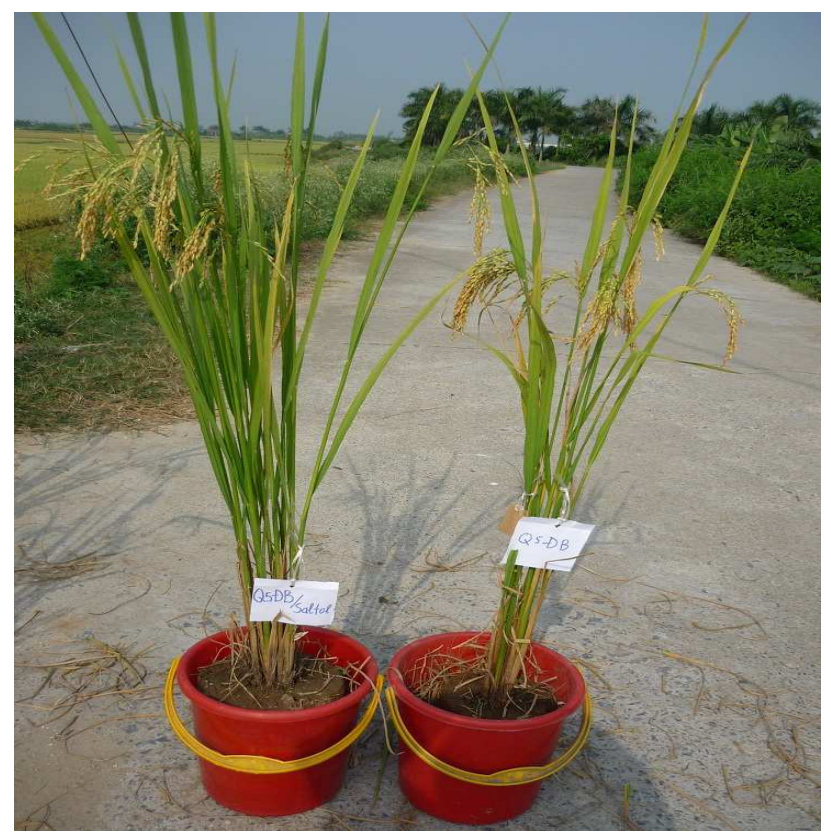

Figure 3. The morphologic of the promising line QF3-1 (Q5DB-Saltol) compared with Q5DB line.

The current study has concentrated on introgressing Saltol QTL into an elite rice variety of Vietnam by applying maker assisted selection techniques. The dominant nature of SSR markers could be very useful in addition to genebased markers for introgression of Saltol QTL into a wide range of recipient elite cultivars ${ }^{(3,6)}$. Our results have indicated that a major salinity tolerance Saltol QTL from the donor parent FL478 was successfully introgressed into Q5DB, an elite rice cultivar of Vietnam. The newly improved lines will be ongoing to disseminate to farmers in the coastal provinces of Vietnamese Deltas for minimizing the risk caused by sea level rise from the climate change.

\section{Conclusions}

Our current work has developed a salinity tolerance of Q5DB variety by using marker assisted selection, which was controlled by a major Saltol QTL. The promising lines QF3-1, QF3-2, QF 4-3-3, QF6-4 of the BC3F2 generation showed significant salt tolerance that was similar with the salt tolerance check of FL478. Moreover, conventional breeding was applied on the BC3F2 for selection of the high yield and high tolerance rice lines. This study could have a good impact on rice breeding, and it is applicable for the introduction of important agronomic trait into the genomes of the popular rice cultivar in Vietnam.

\section{Acknowledgments}

This work has been supported by DANIDA (project code: 09-P01-VIE). The authors would like to thank the staff and students at Vietnam Agricultural Genetics Institute for field work

\section{References}

[1] Munns, R., and Tester, M. Mechanisms of salinity tolerance. Ann Rev Plant Biol., 2008; 59: 651-681.

[2] Nazar, R., Iqbal, N., Masood A., Syeed, S., and Khan, N. A. Understanding the significance of sulfur in improving salinity tolerance in plants. Environ Exp Bot., 2011; 70: 8087.

[3] Khanh, T.D., L.H. Linh., T.H. Linh., L.H. Ham., T.D. Xuan. Rapid and high-precision marker assisted backcrossing to introgress the SUB1 QTL into the Vietnamese elite rice variety. J. Plant Bred Crop Sci., 2013; 5:26-33.

[4] IRRI. The IRRI webpage: http://irri.org/index.php?option=com_(latest accession: May $25,2013)$.

[5] Nguyen, M.H., Thu, P.V., Cuong, N.T.. Evaluation arable soil composition in order to well manage the soil resource of Vietnam. In: Proceedings of the 9th Workshop of Vietnam, Institute of Meteorology Hydrology and Environment., 2006; 9:437-422.

[6] Linh, L.H., Linh, T.H., Xuan, T.D., Ham, L.H., Ismail, A.M., Khanh, T.D.. Molecular breeding to improve salt tolerance of rice (Oryza sativa L.) in the Red River Delta of Vietnam. Inter J Plant Genom., 2012; ID 949039, 9 pages. 
[7] MARD (Ministry of Agriculture and Rural Development). Vietnam News Agency report., 2005.

[8] Singh, D., Kumar, A., Kumar, A., Chauhan, P., Kumar, V., Kumar, N., Singh, A., Mahajan, N., Irohi, P., Chand, S., Ramesh, B., Shin, J., Kumar, P., Kumar, R., Yadav, R..B., Naresh, R.K. Marker assisted selection and crop management for salt tolerance: a review. Afr J Biotech., 2011; 10:14694-14698.

[9] Jena, K.K., Mackill, D.J. Molecular markers and their use in marker assisted selection in rice. Crop Sci., 2008; 48:12661276.

[10] Ben-Ari, G., Lavi, U. Marker assisted selection in plant breeding. In: Plant Biotechnology and Agriculture: Prospects for the 21 st century. Altman, A, Michae, P., Lasegawa., (eds). 2012; 163-184.

[11] Thomson, M.J,, Ismail, A.M., McCouch, S.R., Mackill, M.J. Marker assisted breeding. In: Pareek, A., Sopory, SK, Bohnert HJ, Govindjee., (eds). Abiotic stress adaptation in plants: physiological, molecular and genomic foundation. New York: Springer., 2010; pp. 451-69.

[12] Septiningsih, E.M., Pamplona, A.M., Sanchez, D.L., Neeraja, C.N., Vergar, G.V., Heuer, S., Ismail, A.M., Mackill, D.J. Development of submergence tolerant rice cultivars: the Sub1 locus and beyond. Ann Bot., 2009;103: 151-160.

[13] Singh, R.K,, Redoña, E.D., Refuerzo, L. Varietal improvement for abiotic stress tolerance in crop plants: special reference to salinity in rice. In: Pareek A, Sopory S.K, Bohnert H.J, Govindjee., (eds). Abiotic stress adaptation in plants: physiological, molecular and genomic foundation. New York: Springer., 2010; pp. 387-415.

[14] Bonilla, P., Dvorak, J., Mackill, D., Deal, K., and Gregorio, G. RFLP and SSLP mapping of salinity tolerance genes in chromosome 1 of rice (Oryza sativa L.) using recombinant inbred line. Philip Agric Sci., 2002; 54:68-76.

[15] Ren, Z.H., Gao, J.P., Li, L.G., Cai, X.L., Huang, W., Chao, D.Y., Zhu, M.Z., Wang, Z.Y., Luan, S., Lin, H.X. A rice quantitative trait locus for salt tolerance encodes a sodium transporter. Nature., 2005; 37:1141-1146.
[16] Takehisa, H., Shimodate, T., Fukuta, Y., Ueda, T., Yano, Y., Yamaya, T., Kameya, T., Sato, T. Identification of quantitative trait loci for plant growth of rice in paddy field flooded with salt water. Field Crops Res., 2004; 89:85-95.

[17] Islam, M.R., Gregorio, G.B. Progress of salinity tolerance rice variety development in Bangladesh. Sabrao J Bred Genet., 2013; 45:21-30.

[18] Van Berloo, R.. GGT 2.0: versatile software for visualization and analysis of genetic data. J Hered., 2008; 99:232-236.

[19] Yoshida, S., Forno, D.A., Cock, J.K., Gomez, K.A. Laboratory manual for physiological studies of rice. Manila: International Rice Research Institute; 1976. p. 38.

[20] IRRI. Standard evaluation system for rice. $4^{\text {th }}$ ed. Manila: International Rice Research Institute; 1996. p. 52

[21] Gregorio, G.B., Aliyu, R., Adamu, A.K., Muazu, S., Alonge, S.O. Tagging and Validation of SSR markers to salinity tolerance QTLs in rice (Oryza spp). International conference on biology, environment and chemistry IPCBEE vol 1, IACSIT Press, Singapore, 2010; pp. 328-332.

[22] Mir, R.R., Varshney, R.K.. Future prospects of molecular markers in plants. In: Molecular Markers in plants. Henry R.J., ed 1st, John Wiley \& Sons, Inc. Publisher,. 2013; pp. 169-184.

[23] Niones, J.M. Fine mapping of the salinity tolerance gene on chromosome 1 of rice (Oryza sativa L.) using near- isogenic lines. MS dissertation. Laguna: University of the Philippines Los Baños., 2004: pp.78.

[24] Huyen, L.T.N., Cuc, L.M., Ismail, A.M., Ham, L.H. Introgressiong the salinity tolerance QTLs Saltol into AS996, the elite rice variety of Vietnam. Am J Plant Sci., 2012; 3:891-987.

[25] Hien, V.T.T., Le, D.D., Ismail, A.M., Ham, L.H. Marker assisted backcrossing (MABC) for improved salinity tolerance in rice (Oryza sativa L.) to cope with climate change in Vietnam. Aust J Crop Sci., 2012, 6:1649-1654. 